\title{
'Uncertainty is the only certainty': how pragmatic sociology provides a useful theoretical framework for researching the third sector during COVID-19
}

Janis Petzinger, Tobias Jung, and Kevin Orr

\begin{tabular}{|c|c|}
\hline Date of deposit & 06 April 2021 \\
\hline Document version & Author's accepted manuscript \\
\hline Access rights & $\begin{array}{l}\text { Copyright (c) Policy Press } 2021 \text {. This work is made available online } \\
\text { in accordance with the publisher's policies. This is the author } \\
\text { created, accepted version manuscript following peer review and } \\
\text { may differ slightly from the final published version. }\end{array}$ \\
\hline $\begin{array}{l}\text { Citation for } \\
\text { published version }\end{array}$ & $\begin{array}{l}\text { Petzinger, J., Jung, T., \& Orr, K. (2021). 'Uncertainty is the only } \\
\text { certainty': how pragmatic sociology provides a useful theoretical } \\
\text { framework for researching the third sector during COVID-19. } \\
\text { Voluntary Sector Review, } 12(1), 137-142 \text {. }\end{array}$ \\
\hline $\begin{array}{l}\text { Link to published } \\
\text { version }\end{array}$ & https://doi.org/10.1332/204080521x16101174472905 \\
\hline
\end{tabular}

Full metadata for this item is available in St Andrews Research

Repository at: https://research-repository.st-andrews.ac.uk/

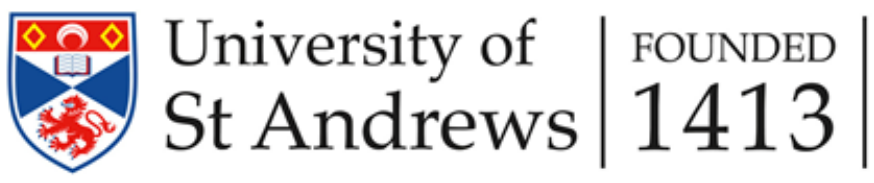




\section{Introduction}

Theoretical frameworks used in third sector research habitually lean towards some kind of stasis or equilibrium. We see this in 'practical truth' approaches that take a positivist, rational tenor to organizations, or in critical theory approaches that focus on society's entrenched systems of power. These methods have their own strengths, depending on the research question, yet COVID - 19 has shown that there are entropic and sometimes contradictory process of change at play (as evident, for instance, in inconsistent national policy, job insecurity, and contradictory science), which our methodologies should account for. But how do we make the old proverb that "the only certainty is uncertainty" a tenable and useful theoretical point of departure within our approach to third sector research?

This research note shows how pragmatic sociology offers an accommodating framework for researching the third sector during COVID - 19 and beyond. It embraces complex and fragile moments in history by examining how actors, in both "macro" and "micro" contexts express and justify their value systems, and by extension, how they express and justify their own contingent practices. This research note demonstrates this by offering background on pragmatic sociology's 'orders of worth' framework, which illustrates how values systems coalesce and then 'test' one another, which results in contingent practice. From here, pragmatic sociology is applied more explicitly in third sector research, ultimately revealing timely research questions to take forward such as: How has COVID - 19 prompted third sector organizations to face difficult judgement calls? What kinds of challenges truly test organizational legitimacy during this time? And how do stakeholders justify their unique practices when responding to such pronounced uncertainty? This note will conclude with the lessons that can be learned from the adoption of pragmatic sociology for third sector research when moving forward in the post-Covid world-whatever that may bring.

\section{Pragmatic sociology and the ordering of worth}

Boltanski and Thévenot first established the field of pragmatic sociology in their seminal book "De la Justification", or, "On Justification", which, at its core, shows how actors justify their practices during moments of conflict. Here, Boltanski and Thévenot draw on their respective backgrounds in sociology and economics to reconcile two dualisms within practice research: the praxeology of Bourdieu, which focuses on critical sociology, versus the actor network theory (ANT) of Latour (Gadinger 2016). Like ANT, pragmatic sociology is not interested in structuralism and believes in the uncertainty of actors; yet pragmatic sociology also expands Bourdieu's critical sociology by making it a 'sociology of critique' (Gadinger, 2016: 188), or more simply, a sociology that uses critique, conflict, and challenge as the nexus of meaning making. It does this by decentering and reifying organizations to a network of values, and then it examines how such value systems 'test' one another through any means of confrontation.

To reduce an organization to a network of values, Boltanski and Thévenot (2006) propose a 
framework called the orders of worth (also sometimes referred to as "the economies of worth" or "the cities of worth"), which proposes that value systems follow some kind of "common superior principle" - or, a shared value upon which people, things, and acts are judged. Various aspects of society, then, follow different orders of worth, which can be reduced to, but are not limited to, six categories: (1) a market order, which values free competition between individuals and ascribes worth to wealth and winners; (2) an inspirational order, in which creative or artistic actors are independent from recognition of others; (3) a domestic order of worth based on values of kinship, family, in which actors respect the traditions of households; (4) a civic order or worth, which venerates people who give up personal interests in favor of the common communal good; (5) an industrial order of worth, which values effectiveness, production, and efficiency of operation systems; (6) and a fame order of worth, which ties to the public reputation of a person. These are deep, contingent expressions of value, found in both big and small expressions of society, from the branding of an organization's firm, to conversations held over dinner.

Some scholars (Silber 2003) have pointed out that pragmatic sociology echoes a Durkheimian approach to research, as it resembles his "systems of morality", and therefore, possibly avoids the concept of individual contingency and interpretive methods. While the orders of worth framework does similarly offer a strong classification structure, it rather functions as a scaffolding for evolving and conditional forms normativity to build upon itself. It therefore surpasses the binaries of structure versus agency, individualism versus collectivism, and sociology versus economics, towards a lens that simply sees critical actors in critical situations (Boltanski and Thévenot 2006). The following section demonstrates these critical situations when expressions of value are 'tested' against one another, which results in a justification of value, or new form of legitimacy.

\section{'Tests': exploring the justification of worth}

Pragmatic sociology's 'tests' refer to the moments when the aforementioned orders of worth 'test' (or challenge) one another in a moment of normative uncertainty. Tests demonstrate what resources actors mobilize during conflict, how they display preexisting or invent new order of worth and means of justification, and how arguing actors manage controversies and disputes (Gadinger 2016). For an action to be justified under this framework, actors need to pass 'tests' that can socially articulate their position. Either they will pass, and their justification will stand, or they will fail, which will then change the social consensus and thus social change will occur. This is done by means of "explaining, clarifying, and, where possible, modeling the methods employed in the social world to make and break bonds." (Boltanski 2011: 25). 'Tests', then, serve as the seed for individual, organizational, or societal change, mirroring Latour's (2005: 23) solution to 'trace connections between the controversies themselves rather than try to decide how to settle any given controversy'. 
When actors within institutions (which are referred to by Boltanski as "bodiless beings") are challenged to renew their credibility during the struggle of tests (Boltanski and Thévenot 2006: 128-158), their critical capacity and reflexivity are revealed. In this way, actor reflexivity is "not separated from action, it is enmeshed within it" (Gadinger 2016: 191) making it a critical moment of value creation, thus prompting the researcher to 'follow the actors', or, treat the experience of actors as central to the main tenant of theory construction (Boltanski and Thévenot 2006: 11-12). This requires an interpretive ontology and an 'on-the-ground' ethnomethodological approach, because the expression and justification of value, for Boltanski and Thévenot, can be found in everyday moments: For instance, gossip between employees at a water cooler, the irritated sighs of executives, or the awkward silences felt during meetings can all be expressions of an organization struggling to adjust to new internal policies.

Furthermore, 'following the actors' means placing all actors on a 'symmetrical plane' (Boltanski and Thévenot 2006) -- or, allowing everyday conflict and tensions to come forth from all parties before assuming an unequal relationship between actors. Rather than assuming that power should be a starting point for inquiry and explanation, embracing a symmetrical plane between actors assumes that the power relations 'can fail even when they succeed', and even the most stable of power relations can be reversed. Importantly, honoring planes of symmetry among all actors, according to Boltanski, also make for more equitable research that does not assume objectivity, and rejects what he describes as "the idea that we can have the last world by producing - and imposing on the actors - more powerful reports than the ones they themselves are able to produce" (Boltanski, 2012: 28). Gadinger (2016) argues that this makes pragmatic sociology an extension of critical theory because it incorporated the actors in the value formation.

If the overall aim of pragmatic sociology is to explore the "justification work" (Jagd 2011: 346) of value systems implemented by actors in situations of conflict, challenge, or uncertainty, how would we apply this to third sector research? The following section explains this in further detail by applying pragmatic sociology to third sector research.

\section{Pragmatic sociology and the third sector: useful research questions}

Pragmatic sociology can uncover everyday critical situations which reveal webs of opposing value. This will bear the organizational dynamism that the third sector is known for (Daly 2011) on both a large and small scale, in some cases by examining seemingly innocuous moments or aspects of an organization. For instance, a hypothetical religious grantmaking foundation (whose mission is of the inspired order) might interpret grant applications of potential grantees via the feasibility and usefulness of work under consideration (of the industrial order), as well as the cost of the project (a market order) but still want to donate money to it depending on its good reputation and how well known it is (the fame order). Here we see the orders of worth framework plot the different vectors of normativity within an organization. This shows that nonprofits, despite maybe having a mission statement that usually portrays what an organization 
values, often do not value just 'one thing' but rather exist in a network of conflicting normativity.

Once normativity is identified within this hypothetical religious charity, the everyday 'tests' that employees undergo are drawn out. This will be found in such research questions as, how do employees discuss how certain grant applications compare to others? What is the basis upon which a grantee is chosen? that will ultimately uncover the delicate ground upon which big, challenging decisions are made within the third sector. Once researchers embrace a position of internal value contingency, pluralism, and uncertainty, then we will begin to unravel the third sector not as an expression of rational practice but as a result of difficult judgment calls. This enables us to rethink commonplace concepts within the third sector and draw out pluralistic interpretation. A worthwhile question to follow here can be, how do notions and expressions of impact differ when organizations follow a market order, versus an industrial order?

Naturally, COVID - 19 sharpens the already typical uncertainty of practice in the third sector as organizations are faced with another layer of complex challenges under the pressure of economic, social, and political uncertainty. To understand these challenges, and how they are being navigated, research questions can explore how the pandemic has challenged practice at an organization. For instance, how does a nonprofit decide to spend more on information technology (IT) compared to its typical spending of mental health services? How do foundations with emergency grant programs justify the spending to their board when the economy is shrinking their investments? How do nonprofits justify their position when they compete for emergency grant programs? These research questions cannot be answered by examining the logical practice of actors, but rather by digging into complexity of the moment at which values are tested.

Research can then examine how the justification of values across organizations demonstrates wider trends. For instance, the justification to spend more on IT for the internal running of an organization, reveals that digital capacity and technology (traditionally seen as luxury items in the world of nonprofits) is now being interpreted as an organizational and personal necessities. It would be useful to compare this macro, large-scale justification to other sectors, or to see how the third sector broadly justifies going into work and keeping their doors open, for instance, compared to the private sector.

\section{A way forward: Pragmatic sociology and the third sector after COVID 19}

Examining value systems and their justification work through pragmatic sociology can remain beneficial once COVID - 19 enters a phase of stability, be it through more straightforward lockdown measures or even by the pandemic ending. One of the main benefits of this theoretical framework carrying researchers through and out of the pandemic is, despite being interpretive and therefore not married to data with a high n-value, it will bring in rich, in-depth, on-the-ground empiricism to the study of the third sector. Highlighting how normativity is expressed and justified will require an ethnomethodologically oriented approach that values thick description and strong research presence, especially given that normative values can be unspoken as much as they are spoken (Boltanski and Thévenot 2006). 
Furthermore, the methodological emphasis on "following the actors" and placing "symmetry" between them reifies third sector institutions into assemblages that include arrangements deriving from different worldviews (Boltanski and Thévenot 2006) - a viewpoint that does not aim see what the third sector is or is not, but rather captures high levels of nuance and contingency. By extension, "following" and assuming a "symmetry" between actors demonstrates the various shades of power beyond the traditional 'top-down' interpretation. Indeed, notions of social, intellectual, and financial power arguably construct these giving relationships, yet pragmatic sociology explores the ways in which critical actors can make the notions of power fluid, complex, and thus, decentered as it negotiates with others, within the self, and within relation to the researcher.

Ultimately, pragmatic sociology enables us to capture what Macmillan (2020: 132) argued needs to emphasized during third sector research during COVID - 19: "a story of dynamic unfolding of change in conditions of uncertainty". Pragmatic sociology's emphasis on 'tests' make such a story possible because it spotlights the how practice unfolds under the challenge of this relentless pandemic: how its effects on relationships within organizations and between; its effects on the way people go into an office and do work; its effects on how nonprofits relate to their mission; its effects on what it now means to have a 'good' quarter. Under pragmatic sociology, then, these contingent moments of uncertainty that make up the third sector, especially during COVID - 19, are no longer aspects of our research to shy away from, but to run towards.

\section{Conclusion}

These research notes have briefly explored the utility of applying pragmatic sociology to the third sector as it uncovers everyday conflicting values of an organization and how these values are tested. This allows for research questions that embrace the volatility of complexity: questions such as how employees give certain grant awards over others, or how organizations interpret impact, uncover the shaky ground upon which significant decisions are made upon. COVID - 19 naturally augments the uncertainty of decision making by constantly testing judgement calls in new ways. Research questions that explore how organizations prioritize funding IT over other services, or how foundations justify more spending during a contracting economy further reveal the evolution of fragile normativity, which can then be compared to other sectors. Even when COVID - 19 cases decline, when social, political, technological, and economic disruption quiets, or even if we someday get comfortable with this 'new normal', fingerprints of hesitation and questioning will likely remain imprinted on the third sector due to the heterogeneous practices that exist within it. But because pragmatic sociology sees diverse value systems as either the precursor or result of tested normativity, uncertainty can be an empirically abundant point of departure for third sector research. 
Bibliography

Boltanski, L. (2011) On Critique: A Sociology of Emancipation, Cambridge: Polity Press.

Boltanski, L. (2012) Love and Justice as Competences, Cambridge: Polity Press.

Boltanski, L. and L. Thévenot (2006). On Justification: Economies of Worth, Princeton, Princeton University Press.

Bourdieu, P. (1996) 'Understanding', Theory, Culture \& Society 13(2): 17-37.

Daly, S. (2011) 'Philanthropy as an Essentially Contested Concept' Voluntas: International Journal of Voluntary and Nonprofit Organizations 23(3): 535-557.

Gadinger, F. (2016) 'On Justification and Critique: Luc Boltanski’s Pragmatic Sociology and International Relations', International Political Sociology 10(3): 187-205.

Jagd, S. (2011) 'Pragmatic sociology and competing orders of worth in organizations.' European Journal of Social Theory, 14(3): 343-359.

Latour, B. (2005) Reassembling the Social, Oxford: Oxford University Press.

Macmillan, R. (2020) 'Somewhere over the rainbow - third sector research in and beyond coronavirus', Voluntary Sector Review, 11(2): 129-136.

Silber, I. F. (2003) 'Pragmatic Sociology as Cultural Sociology: Beyond Repertoire Theory?' European Journal of Social Theory, 6(4): 427-449. 